\section{Comparison of Immediate Effect of New Knee brace and Conventional Three-Points Knee Valgus Brace on Knee Adduction Moment and ROM in Patients with Medial Knee Osteoarthritis}

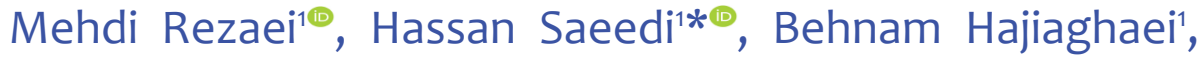 \\ Khosro Khademi-Kalantari², Mokhtar Arazpour ${ }^{3}$
}

\begin{abstract}
The knee unloader brace can change loading on knee which may be effective in reducing symptoms and progression of disease in people with knee osteoarthritis. The purpose of this study was to evaluate the effect of a new knee brace during walking in a patient with medial compartment knee osteoarthritis. Two brace types were used: new brace and conventional brace. A pneumatic cuff of novel brace was fitted in the bottom of the medical slipper that was connected to the cuff section of the knee through the tube. After the knee brace is deployed, its force can vary in different stages of the gait. During the heel strike, the weight of the cuff is compressed on the floor, causing the air to flow inside it and entering the volume of air into the knee pad. The results of using this pneumatic knee brace compared with conventional knee braces on a patient showed that in both cases, the open and closed palatal pump, the adduction moment and ROM was decreased in the stance phase. But the three-point knee pressure, however, was less effective in reducing the adduction moment but also reduced the knee ROM. Using novel brace can eliminate the patient's need for painful and costly surgery to reduce the symptoms of osteoarthritis.
\end{abstract}

Citation: Rezaei M, Saeedi H, Hajiaghaei B, Khademi-Kalantari Kh, Arazpour M. Comparison of Immediate Effect of New Knee brace and Conventional Three-Points Knee Valgus Brace on Knee Adduction Moment and ROM in Patients with Medial Knee Osteoarthritis. J Biomed Phys Eng. 2022;12(4):431-436. doi: 10.31661/jbpe.v0i0.1013.

Keywords

Osteoarthritis, Knee; Braces; ROM; Gait

\section{Introduction}

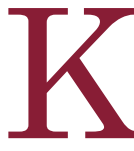

nee osteoarthritis is a debilitating disease in which the joint begins with synovial inflammation and mild pain and changes in

the underlying bones of the cartilage and the edges Knee joint [1]. Osteoarthritis is one of the major causes of disability in older communities. This complication as the third common disease of the elderly is one of the main causes of impotence and pain among the elderly [2]. Studies have shown that $13 \%$ of people aged $64-55$ years and $70 \%$ of $74-65$ years of age experience osteoarthritis in one or more joints [3]; $10 \%$ of men and $21 \%$ of women over 65 years of age with osteoarthritis [4]; it is anticipated that the incidence of this complication will be 600 fold by 2030 [5]. Furthermore, knee osteoarthritis is one of the lower limb disabilities with a prevalence of $3.8 \%$, often associated with pain and motor limitation [6-8], the prevalence of knee osteoarthritis is about 1 percent in the population between 25 and 34 years old, and in the population over 75 , this number reaches 50 percent [9]. The widespread and
${ }^{1} \mathrm{PhD}$, Department of Orthotics and Prosthetics, Iran University of Medical Sciences, Tehran, Is Iamic Republic of Iran ${ }^{2} \mathrm{PhD}$, Department of Physiotherapy, School of Rehabilitation, Shahid Beheshti University of Medical Science, Tehran, Iran

${ }^{3} \mathrm{PhD}$, Orthotics and Prosthetics Department, University of Social Welfare and Rehabilitation Sciences, Tehran, Islamic Republic of Iran

*Corresponding author: Hassan Saeedi

Department of Orthotics and Prosthetics, Iran University of Medical Sciences, Tehran, Islamic Republic of Iran

E-mail: hassan_saeedi2@yahoo.co.uk

Received: 12 September 2018 Accepted: 14 October 2019 
chronic course of this complication has led to the emergence and excitement futuristic various treatment methods in the form of conservative management or surgical interventions [10]. Surgical interventions include knee replacement, osteotomy of the tibia and fusion (if knee replacement is not successful). Surgical treatments are expensive and have inherent complications [11]. Orthoses treatments are the most common conservative treatment in this group of patients, which include the knee brace and lateral wedged insole $[12,13]$. These two interventions are used in patients with knee osteoarthritis as part of the therapeutic process to change the load distribution and to some extent improve knee alignment $[14,15]$.

The results of the studies show that the reduction of adduction moment and forces on the medial compartment of the knee by brace would reduce the pain and improve the performance of patients with knee osteoarthritis $[16,17]$. The amount of effectiveness of knee orthoses on the knee adduction moment and ROM in studies had controversy $[18,19]$. In a study, the reduction of the knee adduction moment was emphasized by the brace during walking, due to the formation of a valgus moment by the brace around the knee joint and thus reducing the force of the medial knee compartment [20]. On the impact of brace on the ROM, studies have shown different results that are likely to depend on how the brace is designed. The results of the study showed that the brace prevents full extension of the knee and thus reduces the ROM [21]. Reducing the range will also reduce the length of the step. In a study, no reduction in motor range and motor restriction was reported by Braise [22]. It should be noted that patients reported some problems by using knee orthoses, such as displacement of orthosis to the distal (migrate distally as a result of muscle contraction). The purpose of this study was to investigate the effect of a new knee brace on the ROM and knee adduction moment and compare it with con- ventional knee braces in a person with knee osteoarthritis.

\section{Material and Methods}

In this study, two types of braces were used and evaluated for a patient including new orthosis and conventional brace. The conventional brace was neoprene knee brace and light weighing less than 500 grams, based on individual measurements. A metal bar on the inside of the knee and a soft pad on the outside of the knee were positioned so that the nonelastic straps were crossed over the hook attached to the metal load is clamped to the soft strap (Figure 1). This brace is applied through the system of three points of pressure to the knee of the valgus force. The designed knee brace structure, as shown in Figure 2, has tight shell, shank shell and pneumatic knee cuff. A pneumatic cuff is also fitted in the bottom of the medical slipper that was connected to the cuff section of the knee through the tube. The cuffs were filled with a manual pump from the air. The knee brace with a pneumatic mechanism can be applied on knee to correct that force. After the knee brace was deployed, its force can vary in different stages of the gait. This brace was associated with the tube to the plantar part of the medical sandals. During the

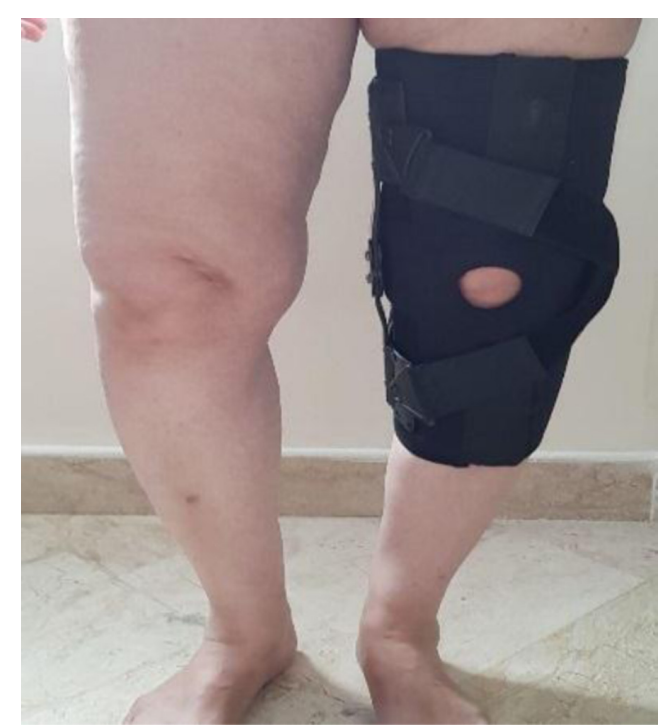

Figure 1: Conventional knee brace 
Innovative Pneumatic Vs Conventional Knee Brace

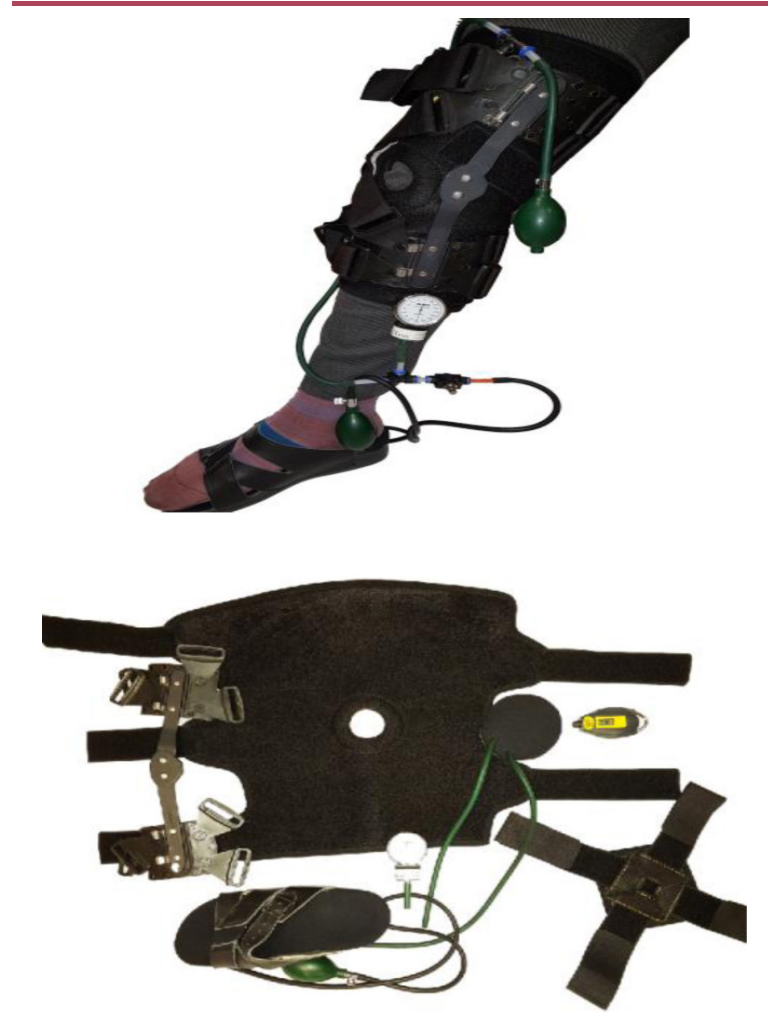

Figure 2: Innovative orthosis

landing force, the foot cuff is pressed in stance level, causing air to flow inside it and entering the volume of air into the knee brace. This force is applied to the knee during weight loss in order to reduce the adduction moment to the affected knee. The volume of air added to the knee cuff returns to the lower cuff with the lifting of the weight at the swing stage; thus, the dynamic compressive force applied on the knee was proportional to the various stages of gait.

\section{Test protocol}

In order to evaluate the effectiveness of brace, both a subjective outcome measure and a biomechanical aspect, a patient with osteoarthritis was studied. The patient was a 50 -year-old woman with a height of $168 \mathrm{~cm}$ and a weight of $80 \mathrm{~kg}$ with knee osteoarthritis; according to the Kolmogorov-Lawrence scale was grade 2 [23]. Gait analysis tests were performed with camera and marker to find out the actual impact of the tool on individual's walk- ing; markering was done in accordance with the Helen Heyse design, 16 markers with a diameter of $14 \mathrm{~mm}$ were attached in the head of the fifth metatarsal, heel, ankle, lateral knee epicondyle, grouter trochanter and PSIS and ASIS and shank (Figure 3).

In this study, a three-dimensional motionanalysis system with six infrared cameras, MXT40-S and two $120-\mathrm{Hz}$ videos for collecting of joint angles were used. The Kistler force plate of $50 \times 30,60 \times 50$ and $1200 \mathrm{~Hz}$ was used to collect ground reaction force data. The moment was calculated using the inverse dynamics model. After the person declared his readiness for the test, the person was first asked to walk 13-meter-long laboratory without brace and the data was recorded and then in two open and closed pump modes with novel orthosis and also the use of three-point pressure knee brace, were recorded for his walk. Each test was repeated 3 times. If the patients were tired during the test, they were allowed to rest. Finally, two variables of knee adduction moment and knee ROM were considered as two main variables.

\section{Results}

In the present study the effect of pneumatic knee brace with both open pump on the adduction moment was more in comparison of other groups. The pneumatic knee brace with the close slipper pump caused a $36 \%$ reduction in the maximum knee adduction moment.

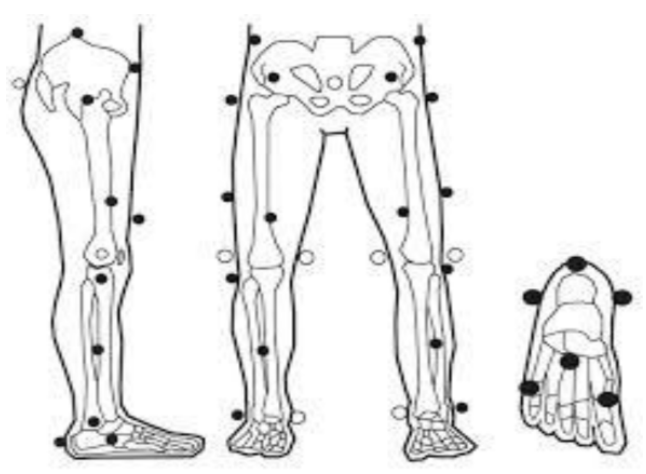

Figure 3: Schematic of markers on the patient's body 
After opening the slipper pump, the maximum reduction in the adduction moment was about $39 \%$, which was about 3\% higher than the close slipper pump position. In the third group, the three-point knee brace also reduced the adduction moment (31\%), although this reduction was lower than the novel brace. Thus, the effect of the novel pneumatic brace with both open pumps (knee and foot pumps) was greater than the three-point knee brace (Table 1).

The knee ROM in the knee joint was reduced by $24 \%$ by using pneumatic knee brace without foot pressure. Using pneumatic knee brace with foot pressure, knee freedom reduced by $17 \%$, which is less compared with Knee brace without foot pressure and indicates the positive effect of the simultaneous opening of both pumps on the knees. When conventional three points knee pressure were used, the degree of freedom on the knee sagittal plane also dropped by $13 \%$, which indicates motion limitation of this innovative knee brace (Table 1).

\section{Discussion}

The results of other studies clearly showed that most braces lead to a reduction in the adduction moment, but the rate of reduction varies in different studies. A study by Johnson et al. which was conducted in 2012 which reported an average of $48 \%$ reduction in the adduction moment, with all of the examined patients having less than 10 degrees of Varus or valgus and Grade 2 or 3 of the Kellgren-Lawrence [23] Other studies conducted by Arazpour et al. in 2014 and Kanaf et al. in 2010 reported a reduction of $7 \%$ and $10 \%$ of adduction moment, respectively, but besides reduction in the adduction moment, pain reduction and daily activity improvement were also ob- served in all patients [24, 25]. The results in a study were accommodated with the results of studies in which brace had no significant effect on the reduction of the adduction moment and the main mechanism of brace seemed to be the reduction of forces in the knee internal compartment and consequently to reduce pain $[26,27]$. In a study conducted in 2013 , Croesus reported $6.6 \%$ reduction of the adduction moment while the airbags were empty and $26 \%$ reduction with full packed bags under the pressure of 7 PSI [28]. In 2006, Gaasbeek reported that the brace effect reduced the adduction moment, but not significantly and the higher the severity of the osteoarthritis, the brace leads to a further decrease in the reduction of the eddy current moment [20]. According to previous studies, one of the defects of braces is the reduction of knee flexion in the phases of swing. It reduces length of step and foot distance from the ground $[29,20]$.

A study found that $42 \%$ of brace were abandoned in the initial year and $64 \%$ in the first three months [30]. This is a negative rating for braces [30,31], which is likely to depend on the size and convenience of brace $[32,33]$. Heaviness and inappropriate appearance is one of the major problems of brace [34, 35].

In general, it can be expressed that either foot pump of pneumatic knee brace was open or closed at both statuses led to knee adduction moment reduction, while a significant reduction in the adduction moment was associated with a significant decrease in the knee ROM. But the three-point knee brace, however, was less effective in adduction moment reducing but also reduced the individual's ROM. This illustrates that reduction in the ROM by the novel pneumatic brace will be reduced by

Table 1: The mean (SD) of the adduction moment and the knee ROM in the sagittal plane

\begin{tabular}{ccccc} 
& $\begin{array}{c}\text { Without } \\
\text { intervention }\end{array}$ & $\begin{array}{c}\text { Three points } \\
\text { knee brace }\end{array}$ & $\begin{array}{c}\text { Pneumatic knee brace; } \\
\text { foot pump was open }\end{array}$ & $\begin{array}{c}\text { Pneumatic knee brace; Knee } \\
\text { and foot pumps were open }\end{array}$ \\
\hline Adduction moment & $0.7(0.04)$ & $0.48(0.09)$ & $0.45(0.19)$ & $0.42(0.12)$ \\
\hline Knee ROM & $44.5(2.13)$ & $38.5(3.87)$ & $33.7(1.32)$ & $36.9(4.44)$
\end{tabular}


Innovative Pneumatic Vs Conventional Knee Brace

simplifying the innovative brace with the new version. It should be noted that statistical analysis and meaningful expression of the changes were not performed due to the low number of people tested in consultation with a statistician in this study.

\section{Conclusion}

The use of a brace inducing simultaneous compression of the foot and knee had a positive effect on reducing the individual's adduction moment which was higher in comparison of other groups, that could be indicative of the relative suitability of the innovative brace in the use of foot pressure. Finally, one could expect to increase patient satisfaction by simplifying the innovative brace. The innovative brace seems to be considered as a solution to knee correction and to control the symptoms of knee osteoarthritis by further investigation and possible defects.

\section{Acknowledgment}

Thanks to Dr. Abbas Rahimi, and Mr. Mehrdad Davoudi for their support during this project.

\section{Authors' Contribution}

H. Saeedi is involved in concept development. M. Rezaei is working on methodology. Results and Analysis was carried out by M. Rezaei and $\mathrm{H}$. Saeedi. The draft was written by M. Rezaei and H. Saeedi. Manuscript was reviewed by M. Arazpour and Kh. Khademi-kalantari. H. Saeedi and B. Hajiaghaei then edited the manuscript. All the authors read, modified, and approved the final version of the manuscript.

\section{Ethical Approval}

The Ethics Committee of Iran University of Medical Sciences approved the protocol of the study (Ethics code: IR.IUMS.FMD.REC 1396.9211503212).

\section{Informed consent}

All participants signed the consent form to participate in the project.
Conflict of Interest

None

\section{References}

1. Altman R, Asch E, Bloch D, Bole G, Borenstein D, Brandt $K$, et al. Development of criteria for the classification and reporting of osteoarthritis. Classification of osteoarthritis of the knee. Diagnostic and Therapeutic Criteria Committee of the American Rheumatism Association. Arthritis Rheum. 1986;29:1039-49. PubMed PMID: 3741515.

2. Englund M. The role of biomechanics in the initiation and progression of $\mathrm{OA}$ of the knee. Best Pract Res Clin Rheumatol. 2010;24:39-46. doi: 10.1016/j. berh.2009.08.008. PubMed PMID: 20129198.

3. Esrafilian A, Karimi MT, Eshraghi A. Design and evaluation of a new type of knee orthosis to align the mediolateral angle of the knee joint with osteoarthritis. Adv Orthop. 2012;2012:104927. doi: 10.1155/2012/104927. PubMed PMID: 22577565. PubMed PMCID: PMC3345217.

4. Bejek Z, Paróczai R, Illyés Á, Kocsis L, Kiss RM. Gait parameters of patients with osteoarthritis of the knee joint. Facta Universitatis-Series: Physical Education and Sport. 2006;4:9-16

5. Kurtz S, Ong K, Lau E, Mowat F, Halpern M. Projections of primary and revision hip and knee arthroplasty in the United States from 2005 to 2030. J Bone Joint Surg Am. 2007;89:780-5. doi: 10.2106/ JBJS.F.00222. PubMed PMID: 17403800.

6. National Institute of Health. National Institute of Arthritis and Musculoskeletal and Skin Disease. NIH; 2010.

7. Jordan KM, Arden NK, Doherty M, Bannwarth B, Bijlsma JW, Dieppe P, et al. EULAR Recommendations 2003: an evidence based approach to the management of knee osteoarthritis: Report of a Task Force of the Standing Committee for International Clinical Studies Including Therapeutic Trials (ESCISIT). Ann Rheum Dis. 2003;62:1145-55. PubMed PMID: 14644851. PubMed PMCID: PMC1754382.

8. Brand A, Klopfer-Kramer I, Morgenstern M, Kroger I, Michel B, Thannheimer A, et al. Effects of knee orthosis adjustment on biomechanical performance and clinical outcome in patients with medial knee osteoarthritis. Prosthet Orthot Int. 2017;41:587-94. doi: 10.1177/0309364617691623. PubMed PMID: 29214918.

9. Jordan JM, Helmick CG, Renner JB, Luta G, Dragomir $A D$, Woodard J, et al. Prevalence of knee symptoms and radiographic and symptomatic knee osteoarthritis in African Americans and Caucasians: the Johnston County Osteoarthritis Project. J Rheumatol. 2007;34:172-80. PubMed PMID: 17216685.

10. Stamenovic D, Kojic M, Stojanovic B, Hunter D. Pneumatic osteoarthritis knee brace. J Biomech Eng. 2009;131:045001. doi: 10.1115/1.3072890. PubMed PMID: 19275449.

11. Zhang W, Moskowitz RW, Nuki G, Abramson S, et al. OARSI recommendations for the management of 
hip and knee osteoarthritis, Part II: OARSI evidencebased, expert consensus guidelines. Osteoarthritis Cartilage 2008;16:137-62. Osteoarthritis Cartilage. 2008;16:1585. doi: 10.1016/j.joca.2008.04.019. PubMed PMID: 18515155.

12. Chuang SH, Huang MH, Chen TW, Weng MC, Liu $\mathrm{CW}$, Chen $\mathrm{CH}$. Effect of knee sleeve on static and dynamic balance in patients with knee osteoarthritis. Kaohsiung J Med Sci. 2007;23:405-11. doi: 10.1016/ S0257-5655(07)70004-4. PubMed PMID: 17666307.

13. Haim A, Rozen N, Dekel S, Halperin N, Wolf A. Control of knee coronal plane moment via modulation of center of pressure: a prospective gait analysis study. $J$ Biomech. 2008;41:3010-6. doi: 10.1016/j.jbiomech.2008.07.029. PubMed PMID: 18805527.

14. Fang MA, Taylor CE, Nouvong A, Masih S, Kao KC, Perell KL. Effects of footwear on medial compartment knee osteoarthritis. J Rehabil Res Dev. 2006;43:42734. PubMed PMID: 17123182.

15. Krohn K. Footwear alterations and bracing as treatments for knee osteoarthritis. Curr Opin Rheumatol. 2005;17:653-6. PubMed PMID: 16093848.

16. Laroche D, Morisset C, Fortunet C, Gremeaux V, Maillefert JF, Ornetti P. Biomechanical effectiveness of a distraction-rotation knee brace in medial knee osteoarthritis: preliminary results. Knee. 2014;21:7106. doi: 10.1016/j.knee.2014.02.015. PubMed PMID: 24642050.

17. Arazpour M, Bani MA, Maleki M, Ghomshe FT, Kashani RV, Hutchins SW. Comparison of the efficacy of laterally wedged insoles and bespoke unloader knee orthoses in treating medial compartment knee osteoarthritis. Prosthet Orthot Int. 2013;37:507. doi: 10.1177/0309364612447094. PubMed PMID: 22864510.

18. Segal NA. Bracing and orthoses: a review of efficacy and mechanical effects for tibiofemoral osteoarthritis. PM R. 2012;4:S89-96. doi: 10.1016/j. pmrj.2012.01.018. PubMed PMID: 22632708.

19. Schmalz T, Knopf E, Drewitz H, Blumentritt S. Analysis of biomechanical effectiveness of valgus-inducing knee brace for osteoarthritis of knee. J Rehabil Res Dev. 2010;47:419-29. PubMed PMID: 20803386.

20. Ramsey DK, Russell ME. Unloader braces for medial compartment knee osteoarthritis: implications on mediating progression. Sports Health. 2009;1:416-26. doi: 10.1177/1941738109343157. PubMed PMID: 23015902. PubMed PMCID: PMC3445170.

21. Gaasbeek RD, Groen BE, Hampsink B, Van Heerwaarden RJ, Duysens J. Valgus bracing in patients with medial compartment osteoarthritis of the knee. A gait analysis study of a new brace. Gait Posture. 2007;26:3-10. doi: 10.1016/j.gaitpost.2006.07.007. PubMed PMID: 16962329.

22. Esrafilian A, Karimi MT, Eshraghi A. Design and evaluation of a new type of knee orthosis to align the mediolateral angle of the knee joint with osteoarthritis. Adv Orthop. 2012;2012:104927. doi: 10.1155/2012/104927. PubMed PMID: 22577565. PubMed PMCID: PMC3345217.
23. Kellgren JH, Lawrence JS. Radiological assessment of osteo-arthrosis. Ann Rheum Dis. 1957;16:494502. PubMed PMID: 13498604. PubMed PMCID: PMC1006995.

24. Johnson AJ, Starr R, Kapadia BH, Bhave A, Mont MA. Gait and clinical improvements with a novel knee brace for knee OA. J Knee Surg. 2013;26:173-8. doi: 10.1055/s-0032-1327452. PubMed PMID: 23288742.

25. Arazpour M, Hutchins SW, Bani MA, Curran S, Aksenov $A$. The influence of a bespoke unloader knee brace on gait in medial compartment osteoarthritis: a pilot study. Prosthet Orthot Int. 2014;38:379-86. doi: 10.1177/0309364613504780. PubMed PMID: 24532004.

26. Schmalz T, Knopf E, Drewitz H, Blumentritt S. Analysis of biomechanical effectiveness of valgus-inducing knee brace for osteoarthritis of knee. J Rehabil Res Dev. 2010;47:419-29. PubMed PMID: 20803386.

27. Hewett TE, Noyes FR, Barber-Westin SD, Heckmann TP. Decrease in knee joint pain and increase in function in patients with medial compartment arthrosis: a prospective analysis of valgus bracing. Orthopedics. 1998;21:131-8. PubMed PMID: 9507265.

28. Otis J, Backus S, Campbell D, Furman G, Garrison G, Warren R, et al. Valgus bracing for knee osteoarthritis: A biomechanical and clinical outcome study. Gait Posture. 2000;11:116-17.

29. Della Croce U, Crapanzano F, Li L, Kasi PK, Patritti $\mathrm{BL}$, Mancinelli C, et al. A preliminary assessment of a novel pneumatic unloading knee brace on the gait mechanics of patients with knee osteoarthritis. PM R. 2013;5:816-24. doi: 10.1016/j.pmrj.2013.06.008. PubMed PMID: 23810812.

30. Brouwer RW, Van Raaij TM, Verhaar JA, Coene LN, Bierma-Zeinstra SM. Brace treatment for osteoarthritis of the knee: a prospective randomized multicentre trial. Osteoarthritis Cartilage. 2006;14:777-83. doi: 10.1016/j.joca.2006.02.004. PubMed PMID: 16563810.

31. Gross KD. Device use: walking AIDS, braces, and orthoses for symptomatic knee osteoarthritis. Clin Geriatr Med. 2010;26:479-502. doi: 10.1016/j. cger.2010.03.007. PubMed PMID: 20699167.

32. Basford JR, Johnson SJ. Form may be as important as function in orthotic acceptance: a case report. Arch Phys Med Rehabil. 2002;83:433-5. PubMed PMID: 11887129.

33. Krohn K. Footwear alterations and bracing as treatments for knee osteoarthritis. Curr Opin Rheumatol. 2005;17:653-6. PubMed PMID: 16093848.

34. Barnes CL, Cawley PW, Hederman B. Effect of CounterForce brace on symptomatic relief in a group of patients with symptomatic unicompartmental osteoarthritis: a prospective 2-year investigation. $A m \mathrm{~J}$ Orthop (Belle Mead, NJ). 2002;31:396-401. PubMed PMID: 12180625.

35. Matsuno H, Kadowaki KM, Tsuji H. Generation II knee bracing for severe medial compartment osteoarthritis of the knee. Arch Phys Med Rehabil. 1997;78:745-9. PubMed PMID: 9228878. 